Article

\title{
Evaluation of Excavation-Damaged Zone around Underground Tunnels by Theoretical Calculation and Field Test Methods
}

\author{
Ming Tao ${ }^{1}$, Zhixian Hong ${ }^{1}$, Kang Peng ${ }^{2, *}$, Pengwei Sun ${ }^{3}$, Mingyu Cao ${ }^{3}$ and Kun Du ${ }^{1,4}$ \\ 1 School of Resources and Safety Engineering, Central South University, Changsha 410083, China; \\ mingtao@csu.edu.cn (M.T.); zhixianh@csu.edu.cn (Z.H.); dukuncsu@csu.edu.cn (K.D.) \\ 2 College of Resources and Environmental Science, Chongqing University, Chongqing 400044, China \\ 3 Fankou Lead-zinc Mine, Shenzhen Zhongjin Lingnan Nonfemet Company Limited, Shaoguan 512325, China; \\ winterspw@163.com (P.S.); 8170142156@163.com (M.C.) \\ 4 Advanced Research Center, Central South University, Changsha 410083, China \\ * Correspondence: pengkang@cqu.edu.cn; Tel.: +86 15974269965
}

Received: 6 March 2019; Accepted: 23 April 2019; Published: 3 May 2019

\begin{abstract}
Excavation-damaged zones (EDZs) induced in underground mining and civil engineering potentially threaten tunnel safety and stability, and increase construction and support costs. In this paper, an investigation of the excavation damaged zone (EDZ) around roadways in Fankou lead-zinc mine in Guangzhou, China is performed by applying a seismic velocity method accompanied by SET-PLT-01 nonmetallic ultrasonic detector. Meanwhile, the in situ stress in the mining area was measured based on the stress relief method with the Swedish high-precision LUT system. The results indicate that the stress field is dominated by the maximum horizontal tectonic stress, and the extents of the EDZ on the roof-floor region are greater than that on the sidewall. In addition, both of the in situ stresses and EDZs show an increasing trend with an increase of depth. Analytical solutions of EDZ around circular openings in the brittle rock mass subjected to non-hydrostatic stress fields are presented in terms of the Mohr-Coulomb and generalized Hoek-Brown criteria, and validated by several cases mentioned above. The extents of EDZ solved by closed-form solutions were found to be in a great agreement with those obtained in the field. Finally, a series of parametric studies are conducted to investigate the effects of cohesion $(c)$, friction angle $(\varphi)$, geological strength index $(G S I), m_{i}$, uniaxial compressive strength $\left(\sigma_{c}\right)$, and disturbance factor $(D)$ on EDZ. It is shown that the effects of $c, \varphi, G S I$, and $\sigma_{c}$ are significant; however, more attention should be paid to consider the dynamic disturbances induced by mechanical drilling, blasting, and seismic waves in tunnel excavations or operations.
\end{abstract}

Keywords: excavation-damaged zone; closed-form solution; in situ stress; on-site measurement

\section{Introduction}

The supply of energy is related to the lifeblood of global economic development. As one of the important components of energy, mineral resources are rapidly decreasing in the shallow crust. Therefore, in order to ensure sustainable human production activities, a number of mines are gradually shifting to deep mining around the world. It is well known that in situ stress redistribution will be generated during the excavation progress of a man-made opening, then the tangential stress gradually increases while radial stress on the surrounding rock mass decreases. Both of them reach an extreme state on the surface of the openings and therefore stress concentrations occur in the surrounding of the openings. Once the concentrated stress exceeds the failure strength of the surrounding rocks, excavation-induced cracks are initiated and gradually expand deep into the rock mass until the stress 
reaches a new equilibrium condition. Eventually, an undesirable excavation-damaged zone (EDZ) where the basic physical, thermal-mechanical, and hydrogeological properties of surrounding rocks are greatly changed is induced in the rock mass surrounding the opening during the construction process [1-4]. Previous studies have indicated that geohazards, such as roof collapse, rheology, and floor sinking are related to EDZs [5-8], which threaten the safety and efficiency of deep underground mining. Therefore, it is important to develop a solution and measurement method to determine the mechanism of EDZ development and accurately evaluate the thickness of an EDZ.

Extensive studies have been conducted on evaluating the EDZs based on theoretical analysis, numerical simulation, and field test [9-12]. Wu et al. [13] introduced a simplified formula for assessing an EDZ according to the strain energy density released due to excavation. However, closed-form solutions of stress and displacement distributions around circular openings are mainly based on different constitutive models and failure criteria. The Mohr-Coulomb and Hoek-Brown failure criteria are simultaneously employed to analyze circular tunnel problems. For instance, the theoretically consistent closed-form solution of displacements around a circular opening under an elastic-brittle-plastic rock mass satisfying the Hoek-Brown failure criterion is proposed [14,15]. Carranza-Torres [16] developed a perfectly elastic-plastic constitutive model and effectively combined it with the Hoek-Brown criterion. Park et al. [17] proposed analytical solutions for predicting displacements around a circular opening in terms of both the Mohr-Coulomb and Hoek-Brown failure criteria. However, these criteria do not consider the effect of intermediate principal stress. Because of this deficiency, researchers have started using the Drucker-Prager criterion and unified strength theory to solve the elastic-plastic problem of surrounding rocks in circular openings. Based on the unified strength theory and the hypothesis of plane strain, Roatesi et al. [18] proposed a new closed-form solution and a specific expression for the circular tunnel problem in finite and infinite rock masses, respectively. Moreover, they analyzed the effect of the intermediate principal stress, radius-dependent Young's modulus, and dilatation on the stress and displacement fields of EDZs. The results indicate that stress and radial displacement decrease with the increase in the intermediate principal stress parameter, $b$. More recently, Singh et al. [19] proposed analytical solutions for the circular opening problem in an elastoplastic rock mass under the Mogi-Coulomb, inscribed Drucker-Prager, middle circumscribed Drucker-Prager, circumscribed Drucker-Prager, and Mohr-Coulomb failure criteria. In addition, considering the effect of the intermediate principal stress and selection of the appropriate failure criteria have a significant effect on optimizing the support system. Several studies have investigated the effect of out-of-plane stresses on tunnel problems in elastoplastic rock masses [20-23]. Based on the nature of a non-plane strain problem, an analytical solution of the cylindrical opening subjected to various in situ axial stresses can be derived by employing the Mohr-Coulomb failure criterion [24].

In conjunction with the development of high-speed computer algorithms, numerical simulation, as an effective method in geotechnical engineering [25-28], has been widely applied to investigate EDZs. Golshani et al. [29] simulated the excavation damage of a circular opening in a brittle rock mass in terms of an extended micromechanics-based continuum damage model. The results clearly show that the development of an EDZ is a function of time and that moisture has a significant effect on its development. Moreover, an EDZ formed in the sidewalls is larger when the vertical stress is greater than the horizontal stress. Yang et al. [30] studied the relationship between EDZ size and the excavation process, lining, rock mass structure, initial stress, and tunnel radius. Perras et al. [31] evaluated the validity of the damage initiation and spalling limit approach for predicting the depth of the damaged area, as well as the predictive equations for the EDZ range of circular tunnels in the brittle rock mass. Based on the Flac3d platform, Ren et al. [32] investigated the surrounding rock displacement field, stress field, and plastic damage zone by developing an elastic-plastic damage numerical method for fractured rock mass, which can be effectively applied to optimize the excavation scheme of URL. Other numerical studies show that the effect of lateral stress ratio and high in-situ stress are closed related to the excavation damaged zone $[33,34]$. 
As discussed above, several analytical and numerical solutions have been introduced to assess and characterize EDZs around circular roadways under hydrostatic pressure. However, knowledge available in the literature concerning closed-form solutions of elastoplastic problems around circular openings subjected to asymmetrical stress conditions is still limited. Therefore, the present study attempted to evaluate the EDZ in Fankou lead-zinc mine in terms of theoretical calculation and field test methods. The investigation of the distribution law of in situ stress field and EDZ in the mining area is conducted. Closed-form solutions are derived for predicting the radius of EDZ around a circular opening in brittle rock mass under non-hydrostatic stress field based on the Mohr-Coulomb and generalized Hoek-Brown failure criteria. Then the accuracy of presented analytical solutions are validated by comparing the thickness of EDZ measured in the field with the single-hole seismic velocity method. In addition, a parametric study of $c, \varphi, G S I, m_{i}, D$, and $\sigma_{c}$ on the damaged zone is carried out. The results of this study show that both the in situ stresses and the thickness of EDZ increase with the depth. Great agreement between the measured and calculated thickness of EDZ is obtained. The findings can provide measures to control damage zones and can also provide theoretical guidance for underground tunnel excavation and support.

\section{Closed-Form Solutions of EDZ around Circular Tunnels}

In general, closed-form solutions for circular tunnel problems are derived on the assumption that a tunnel is subjected to a hydrostatic stress field. Nevertheless, the initial stress in the surrounding rock mass has to be considered as inhomogeneous in most practical situations; that is, the lateral pressure coefficient is not equal to $(\lambda \neq 1)$ one. Two expressions are presented in this paper for predicting the extent of an EDZ around a circular tunnel in an infinite elastoplastic rock mass, which is governed by a non-hydrostatic pressure and obeys both the Mohr-Coulomb and Hoek-Brown failure criteria.

As shown in Figure 1, where $r$ is the radial distance from the center of the opening surface, and $R_{p}$ is the plastic zone radius, a circular tunnel of radius $R_{0}$ in an infinite elastoplastic rock mass is subjected to a stress field of vertical stress, $\sigma_{0}$, and horizontal stress, $\lambda \sigma_{0}$. The support resistance and fluid containment distributed on the tunnel wall are assumed to be zero and can be simplified as a plane strain problem in the cylindrical coordinate system.

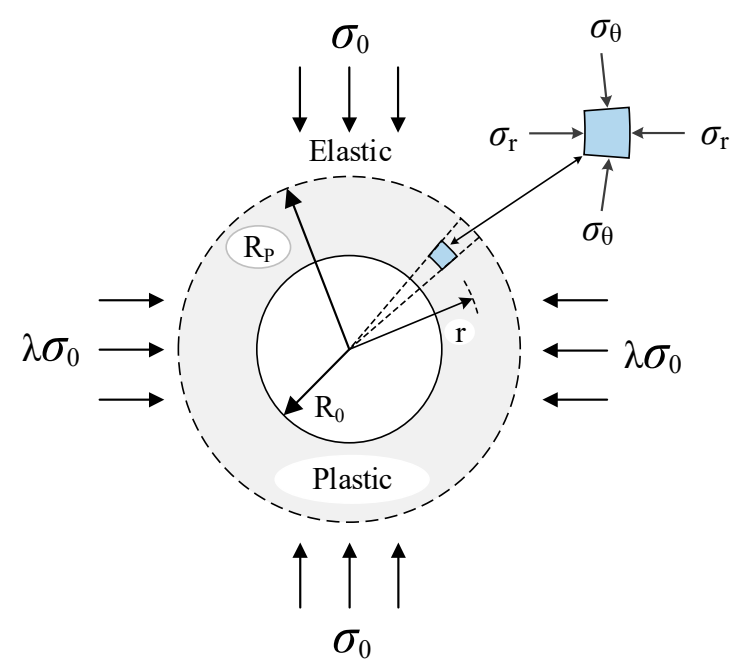

Figure 1. Circular tunnel in an elastic-plastic material subjected to inhomogeneous stress. 
In fact, when $r>R_{p}$, the radial and tangential stresses are independent of the rock mass failure criterion and are only related to the initial stress state of the rock mass. Therefore, the stresses in the elastic zone can be obtained directly based on the theory of elasticity:

$$
\left\{\begin{array}{l}
\sigma_{r}^{e}=S_{1}\left(1-\mu^{2}\right)+\mu \sigma_{i}-S_{2}\left(1-4 \mu^{2}+3 \mu^{4}\right) \cos 2 \theta \\
\sigma_{\theta}^{e}=S_{1}\left(1+\mu^{2}\right)-\mu \sigma_{i}+S_{2}\left(1+3 \mu^{2}\right) \cos 2 \theta
\end{array}\right.
$$

where $\sigma_{r}^{e}$ and $\sigma_{\theta}^{e}$ are the radial and tangential stresses in the elastic zone, respectively, $\sigma_{i}$ represents the radial stress on the elastic-plastic interface, and $S_{1}=(1+\lambda) \sigma_{0} / 2, S_{2}=(1-\lambda) \sigma_{0} / 2$, and $\mu=R_{p} / r$.

The stresses in the plastic zone can be solved in terms of the failure criteria and equilibrium Equation [2]:

$$
\frac{d \sigma_{r}}{d r}+\frac{\sigma_{r}-\sigma_{\theta}}{r}=0
$$

\subsection{Extent of the Plastic Zone in Terms of the Mohr-Coulomb Failure Criterion}

In 1900, Mohr and Coulomb proposed the Mohr-Coulomb strength theory, which can characterize changes in rock strength with the surrounding rock pressure. It has been employed extensively in expressing the shear failure of rock materials because of its remarkable advantages, specifically, its simplicity and wide variety of classical plasticity solutions. For an active loading condition, the Mohr-Coulomb failure criterion can be written as [35]

$$
\sigma_{\theta}=\omega_{1} \sigma_{r}+\omega_{2}
$$

where $\omega_{1}=(1+\sin \varphi) /(1-\sin \varphi), \omega_{2}=2 c \cdot \cos \varphi /(1-\sin \varphi)$; and $c$ and $\varphi$ represent the cohesion and friction angle of the rock mass, respectively.

By substituting Equation (3) into (2), then combining them with the boundary condition $\sigma_{\mathrm{r}}=0$ when $r=R_{0}$, the expressions for radial and tangential stresses in the plastic zone are derived as

$$
\left\{\begin{aligned}
\sigma_{r}^{p} & =c \cot \varphi\left[\left(\frac{r}{R_{0}}\right)^{\xi}-1\right] \\
\sigma_{\theta}^{p} & =c \cot \varphi\left[\omega_{1}\left(\frac{r}{R_{0}}\right)^{\xi}-1\right]
\end{aligned}\right.
$$

where $\zeta=2 \sin \varphi /(1-\sin \varphi)$.

On the elastic-plastic interface $\left(r=R_{p}\right)$, the stress states $\sigma_{i}=\sigma_{r}$ and $\sigma_{\theta}=2 S_{1}-\sigma r+4 S_{2} \cos 2 \theta$, satisfy the Mohr-Coulomb failure criterion. Thus, by substituting $\sigma_{\theta}$ into Equation (3), $\sigma_{i}$ is given by

$$
\sigma_{i}=\frac{2 S_{1}+4 S_{2} \cos 2 \theta-\omega_{2}}{\omega_{1}+1}
$$

With the continuous conditions of stress on the elastic-plastic zone interface $\left(\sigma_{r}^{p}=\sigma_{r}^{e}, \sigma_{\theta}^{p}=\sigma_{\theta}^{e}\right)$, the extent of the plastic zone around the circular tunnel in the rock mass governed by the Mohr-Coulomb failure can be obtained by combining Equations (1) and (4) with (5):

$$
R_{p}^{M-C}=R_{0}\left[A \cdot\left(\frac{2 S_{1}+4 S_{2} \cos 2 \theta}{B}+1\right)\right]^{\frac{1}{\xi}}
$$

where $A=1-\sin \varphi$ and $B=2 c \cdot \cot \varphi$.

\subsection{Extent of Plastic Zone in Terms of the Hoek-Brown Failure Criterion}

In 1980, Hoek and Brown proposed the Hoek-Brown failure criterion based on their experiments and projects. Soon thereafter, Hoek et al. modified the primary criterion by introducing the 
concept of disturbed and undisturbed rock masses in 1992. The generalized Hoek-Brown criterion is given by [36-38].

$$
\sigma_{1}=\sigma_{3}+\sigma_{c}\left(m_{g} \frac{\sigma_{3}}{\sigma_{c}}+\delta\right)^{\alpha}
$$

where $\sigma_{1}$ and $\sigma_{3}$ represent the major principal stress and minor principal stress at failure, respectively; $\sigma_{\mathcal{C}}$ is the uniaxial compressive strength of the intact rock; $m_{g}, \delta$, and $\alpha$ are the Hoek-Brown constants, which depend on the properties of the rock mass. In cylindrical coordinates, for an active condition, Equation (7) can be written as

$$
\sigma_{\theta}=\sigma_{r}+\sigma_{c}\left(m_{g} \frac{\sigma_{r}}{\sigma_{c}}+\delta\right)^{\alpha}
$$

The coefficients $m_{g}, \delta$, and $\alpha$ are calculated based on the empirical index called the geological strength index (GSI). This index can be quantified from charts based on the quality of the rock structure and condition of rock surfaces. The rock mass parameters are expressed according to the Carranza-Torres model [14]

$$
\begin{gathered}
m_{g}=m_{i} \exp \left(\frac{G S I-100}{24-14 D}\right) \\
\delta=\exp \left(\frac{G S I-100}{9-3 D}\right) \\
\alpha=0.5+\frac{1}{6}\left[\exp \left(\frac{-G S I}{15}\right)-\exp \left(\frac{-20}{3}\right)\right]
\end{gathered}
$$

In Equations (9) and (10), $m_{i}$ is the coefficient, $D$ is the factor that reflects the degree of disturbance to which the rock mass has been subjected because of blast damage and stress relaxation. It varies between 0 and 1 . Actually, in the analytical solution of a circular tunnel problem, deducing when $\alpha>0.5$ is not straightforward. Therefore, in a relatively good quality rock mass, it is assumed that $\alpha=0.5$.

The stresses in the radial and tangential directions in the plastic region can be described according to Equations (2) and (8)-(11). Then combining them with the boundary condition $\sigma_{r}=0$ when $r=R_{0}$, the following is obtained:

$$
\left\{\begin{array}{c}
\sigma_{r}^{p}=\left(\frac{C}{2}+\sqrt{\delta}\right)^{2} E-\delta E \\
\sigma_{\theta}^{p}=\left\{\frac{C}{2}+\sqrt{\delta}\right\}^{2} E-\delta E+\sigma_{c}\left(\frac{C}{2}+\sqrt{\delta}\right)
\end{array}\right.
$$

where $C=m_{g} \ln \left(r / R_{0}\right)$ and $E=\sigma_{c} / m_{g}$.

At the elastic-plastic interface $\left(r=R_{p}\right), \sigma_{i}=\sigma_{r}$, and $\sigma_{\theta}=2 S_{1}-\sigma_{r}+4 S_{2} \cos 2 \theta$. The radial stress is obtained in terms of the Hoek-Brown failure criterion through the substitution of $\sigma_{\theta}$ into Equations (8)-(11):

$$
\sigma_{i}=K+\frac{\sigma_{c}}{8}\left(m_{g}-J\right)
$$

where $K=S_{1}+2 S_{2} \cos 2 \theta$ and $J=\left(m_{g}^{2}+16 \delta+16 m_{g} K / \sigma_{c}\right)^{0.5}$.

With the continuous conditions of stress at the elastic-plastic interface $\left(\sigma_{r}^{p}=\sigma_{r}^{e}, \sigma_{\theta}^{p}=\sigma_{\theta}^{e}\right)$, a closed-form solution of the extent of damage in the plastic zone within the surrounding rock mass, which satisfies the Hoek-Brown failure criterion, can be obtained by combining Equations (1) and (12) with (13):

$$
R_{p}^{H-B}=R_{0} \exp \left\{F\left[\left(\frac{K}{E}+H-\frac{J m_{g}}{8}\right)^{0.5}-\sqrt{\delta}\right]\right\}
$$

where $H=\delta+m_{g}^{2} / 8$ and $F=2 / m_{g}$.

\section{Fankou Lead-Zinc Mine in Situ Stress Distribution Laws}

An investigation of the distribution law of in situ stress field was performed in Fankou lead-zinc mine in Guangzhou, China where the average elevation is approximately 100 to $200 \mathrm{~m}$. The mine is currently operating with the vertical crater retreat (VCR) mining method at depths from $80 \mathrm{~m}$ 
to $880 \mathrm{~m}$ below the ground surface. The ore contains a large amount of yellow iron lead-zinc ores incorporating massive pyrite, the main components of the surrounding rock are massive and porphyritic limestone, dolomitic marl, and nodular limestone. The basic physical and mechanical properties of the surrounding rocks and ores were determined by laboratory tests of specimens extracted from exploration drilling cores and rock blocks taken directly from Fankou lead-zinc mine, experimental results showed that the uniaxial compressive strength, Poisson's ratio, and Platts' coefficient of rocks in this mining area were approximately $130 \mathrm{MPa}, 0.25$, and 8 to 13, respectively. Evidently, their stability was generally good, and typically, there was no need to design a support system for the upper ore body.

Numerous measurements of in situ stresses in the mining areas were carried out by applying the Swedish high-precision LUT rock triaxial stress measurement system which is with a basic principle of overcoring. Based on the assumption of linear and elastic deformations in the surrounding rock mass around boreholes, as well as the coincidence of loading and unloading curves, the main steps of field measurement are briefly described below. Boreholes deepened into the rock mass is firstly drilled, then twelve strain gauges are stuck firmly on the surface of drilling borehole. Meanwhile, the initial strain of each strain gauge is set to zero. Secondly, recovering the elastic deformation of the cores by releasing the surrounding rock stress with the overcoring method and measuring the elastic recovery strain of the cores. Finally, according to the measured elastic recovery strain and elastic constant of the rock mass, the stress conditions of each measurement site, including the stress component and principal stress, are analyzed by employing a specific LUT-str rock mass stress calculation program, the magnitude and direction of in situ stresses can be solved out with high accuracy.

The maximum horizontal principal stress, $\sigma_{h \text {-max }}$ minimum horizontal principal stress, $\sigma_{\mathrm{h} \text {-min }}$; and vertical principal stress, $\sigma_{v}$, were calculated by inputting the drilling parameters, elastic parameters, and recovered strain into the LUT-str calculation systems. Moreover, the ratio of $\sigma_{h \text {-max }}$ to $\sigma_{h-\min }$ and the ratio of $\sigma_{h-\max }$ to $\sigma_{v}$ were also calculated, as summarized in Table 1 .

Table 1. In situ stresses of each measurement sites.

\begin{tabular}{cccccccccc}
\hline No. & Depth/m & $\sigma_{h-\max } / \mathbf{M P a}$ & $\begin{array}{c}\text { Average } \\
\sigma_{h-\text { max }} / \mathbf{M P a}\end{array}$ & $\sigma_{h-\min } / \mathbf{M P a}$ & $\begin{array}{c}\text { Average } \\
\sigma_{h-\min } / \mathbf{M P a}\end{array}$ & $\sigma_{v} / \mathbf{M P a}$ & $\begin{array}{c}\text { Average } \\
\sigma_{v} / \mathbf{M P a}\end{array}$ & $\sigma_{h-\max } / \sigma_{v}$ & $\sigma_{h-\max } / \sigma_{h-\min }$ \\
\hline $1^{\#}$ & 370 & 17.96 & & 7.35 & & 9.66 & & 1.860 & 2.44 \\
$2^{\#}$ & 370 & 18.79 & 18.93 & 9.16 & 9.20 & 10.28 & 10.39 & 1.827 & 2.05 \\
$3^{\#}$ & 370 & 20.03 & & 11.08 & & 11.23 & & 1.784 & 1.81 \\
$4^{\#}$ & 450 & 22.30 & & 9.79 & & 12.10 & & 1.843 & 2.28 \\
$5^{\#}$ & 450 & 22.84 & 23.00 & 11.22 & 11.24 & 12.80 & 12.82 & 1.78 & 2.04 \\
$6^{\#}$ & 450 & 23.88 & & 12.72 & & 13.56 & & 1.76 & 1.88 \\
$7^{\#}$ & 530 & 24.62 & & 12.62 & & 13.55 & & 1.82 & 1.95 \\
$8^{\#}$ & 530 & 26.88 & 27.12 & 12.98 & 12.97 & 15.12 & 15.39 & 1.78 & 2.07 \\
$9^{\#}$ & 530 & 29.85 & & 13.29 & & 17.48 & & 1.71 & 2.25 \\
$10^{\#}$ & 680 & 33.25 & & 15.02 & & 17.94 & & 1.85 & 2.21 \\
$11^{\#}$ & 680 & 34.67 & 34.63 & 17.16 & 17.17 & 19.77 & 19.80 & 1.75 & 2.02 \\
$12^{\#}$ & 680 & 35.96 & & 19.34 & & 21.68 & & 1.66 & 1.86 \\
$13^{\#}$ & 780 & 37.09 & & 18.98 & & 22.34 & & 1.66 & 1.95 \\
$14^{\#}$ & 780 & 39.73 & 39.36 & 19.74 & 19.63 & 22.37 & 22.78 & 1.78 & 2.01 \\
$15^{\#}$ & 780 & 41.27 & & 20.15 & & 23.62 & & 1.75 & 2.05 \\
\hline
\end{tabular}

It can be seen from Table 1 that the maximum horizontal, minimum horizontal, and vertical principal stresses present an increasing trend in the mining area, and the in situ stress field in the Fankou lead-zinc mine was dominated by horizontal tectonic stresses. At the same overburden depth, because there was no evident difference among the magnitudes of the same type of stresses at different measurement points, the in situ stresses in the mining area were relatively uniform. In addition, the ratio of $\sigma_{h-\max }$ to $\sigma_{v}$ in the mining area was approximately 1.80 , and it gradually decreased as the excavation depth increased. The results indicate that as the depth increased, the effect of the gravitational stress on in situ stresses became more significant. On the other hand, it is noteworthy that the ratio of $\sigma_{h \text {-max }}$ to $\sigma_{h \text {-min }}$ was approximately 1.81 to 2.44 . This revealed that the distribution law of horizontal tectonic stress in the rock mass is related to the depth. 
In order to visualize the relationship between in situ stresses and depth, the least-square method was employed to conduct a linear regression analysis of the stress data measured in the field. The regression equations of the relationship between $\sigma_{h . m a x}, \sigma_{h, \min }$, and $\sigma_{v}$, and the depth of the measurement stations are expressed as

$$
\begin{gathered}
\sigma_{h, \max }=0.2654+0.0506 H \\
\sigma_{h, \min }=-0.3862+0.0258 H \\
\sigma_{v}=-0.2457+0.029 H
\end{gathered}
$$

where $H$ is the overburden depth of measurement sites.

\section{Investigations of EDZ in the Fankou Lead-Zinc Mine}

\subsection{Test Method and Apparatus}

So far, many in situ test methods of EDZs have been invented to adapt to complex geological conditions [13,39-41]. Whereas, because of better adaptability and operability, nonmetallic ultrasonic detection techniques are still widely used in mining and civil engineering [42]. In this study, the single-hole acoustic wave monitoring method incorporating a SET-PLT-01 nonmetallic ultrasonic detector was applied. This testing system is mainly comprised of a host computer, a water container, an ultrasonic source probe, and two receiving probes. The nonmetallic ultrasonic detector is relatively easy to operate and highly adaptable. In particular, it improves the testing environment and overcomes the shortcoming of the fully water-coupled acoustic wave test method, which cannot be used in a severely fractured rock mass. A simple illustration of the principle of the single-hole ultrasonic detection technique is shown in Figure 2.

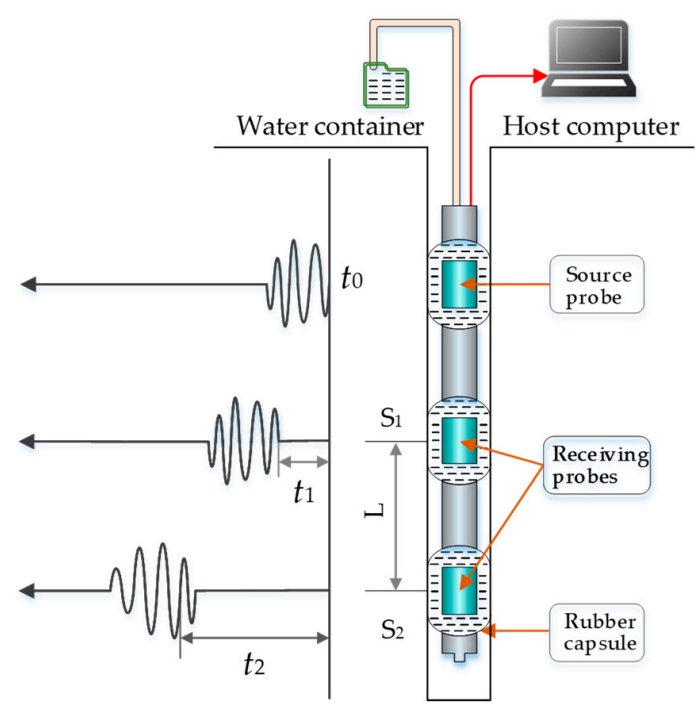

Figure 2. Principle of ultrasonic testing.

The source and receiving probes were inserted into the boreholes. This triggered the source probes to generate ultrasonic waves, which were refracted several times and received by probes S1 and S2. The waves were finally converted into electrical signals and stored in the host computer. Then data from all monitored points along each borehole were processed to obtain the depth and wave velocity curves. The formulation of the wave velocity at each monitored point can be expressed as

$$
v_{p}=\frac{L}{t_{1}-t_{2}}
$$


where $t_{1}$ and $t_{2}$ represent the initial times when receiving probes $S_{1}$ and $S_{2}$ start receiving signals, respectively, and $\mathrm{L}$ is the distance between the two receiving probes.

The velocity of the ultrasonic waves decreased with the development of fractures. That is, the wave velocity was high if the surrounding rocks were intact; otherwise, the velocity was low. Hence, the thicknesses of EDZs around roadways can be determined by analyzing wave velocity variations at various locations.

\subsection{Field Measurements}

A total of five monitoring roadways with 20 test sites in the mining area were selected for EDZ assessment. These roadways were arch-shaped and had neither support nor serious disturbance. The locations and borehole parameters of these detection stations are summarized in Table 2.

Table 2. Locations and parameters of five monitoring roadways.

\begin{tabular}{cccccc}
\hline Number & $\begin{array}{c}\text { Overburden } \\
\text { Depth }(\mathbf{m})\end{array}$ & Roadway Type & $\begin{array}{c}\text { Equivalent Radius } \\
\text { of Tunnels }(\mathbf{m})\end{array}$ & $\begin{array}{c}\text { Boreholes } \\
\text { Diameter (mm) }\end{array}$ & $\begin{array}{c}\text { Boreholes } \\
\text { Depth (m) }\end{array}$ \\
\hline I & 370 & Ventilation roadway & 2.70 & 51 & 3.2 \\
II & 450 & Haulage roadway & 2.45 & 51 & 3.2 \\
III & 530 & Main track roadway & 2.80 & 51 & 3.2 \\
IV & 680 & Across-vein roadway & 2.00 & 51 & 3.2 \\
V & 780 & Main return-air roadway & 2.40 & 51 & 3.2 \\
\hline
\end{tabular}

Four test boreholes were symmetrically drilled on the left and right sides of the roadways. The borehole depths were from 2.0 to $3.2 \mathrm{~m}$, with a diameter of $51 \mathrm{~mm}$ and an inclination angle of $30^{\circ}$. The measurements were performed along the detecting borehole at an interval of $0.1 \mathrm{~m}$ from top to bottom. The arrangement of the boreholes monitored with the SET-PLT-01 nonmetallic ultrasonic detector around the roadways is shown in Figure 3.

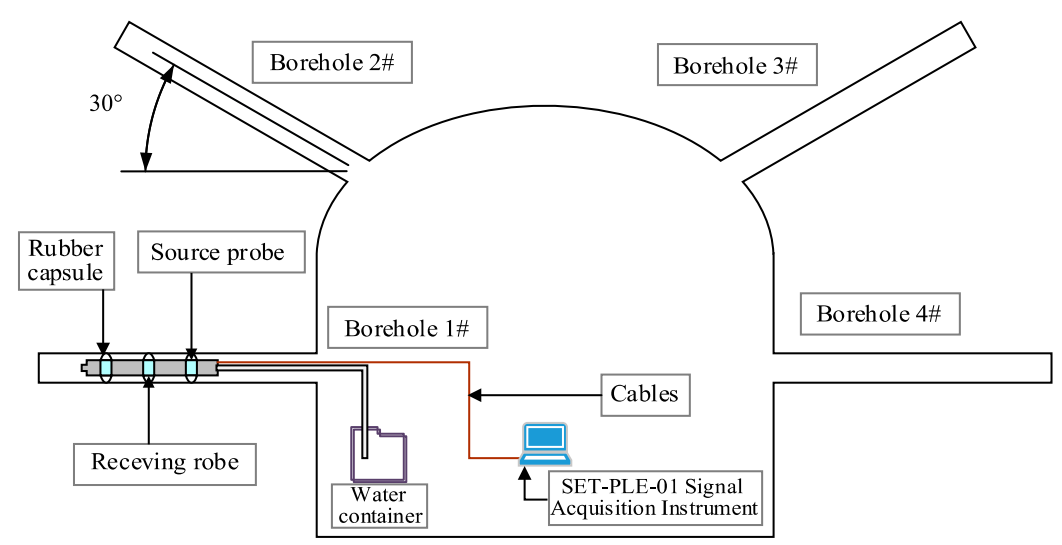

Figure 3. The arrangement of monitored boreholes around roadways.

The main steps involved in field-testing with the application of the dry single-hole ultrasonic detection technology are briefly introduced below. The drilling boreholes are firstly flushed with high-pressure water on account of the rough surface and a considerable amount of debris, then water is injected into the charging pipe by compressing the container until water overflowed continuously from the vent hole. Simultaneously, the vent is sealed with screws, and gas is prevented from entering the pipe. Secondly, the valve is opened to allow water to return to the container. Thereafter, the monitoring detector is thrust into the borehole and water is supplied into it until the rubber capsule is fully in contact with the surface of the borehole. Thirdly, to ensure accurate data collection, parameters such as the pulse width and frequency were adjusted. Finally, the data should be collected and saved when the 
signals become stable. It should be noted that the first measurement point is set at a distance of 0.2 to $0.4 \mathrm{~m}$ away from the sidewall because of the extreme fragmentation of rocks near the roadway surface.

\subsection{Measurement Results and EDZ Analysis}

Variation curves of the wave velocity with depth, shown in Figure 4, were obtained by loading the saved data into the special analysis software. According to these variation curves, the ultrasonic wave velocity increased as the borehole depth increased. In fact, the wave velocity was low because of the large number of cracks induced near the orifice; in contrast, it was high and stable when the monitoring points were located considerably far from the orifice until the joints closed.

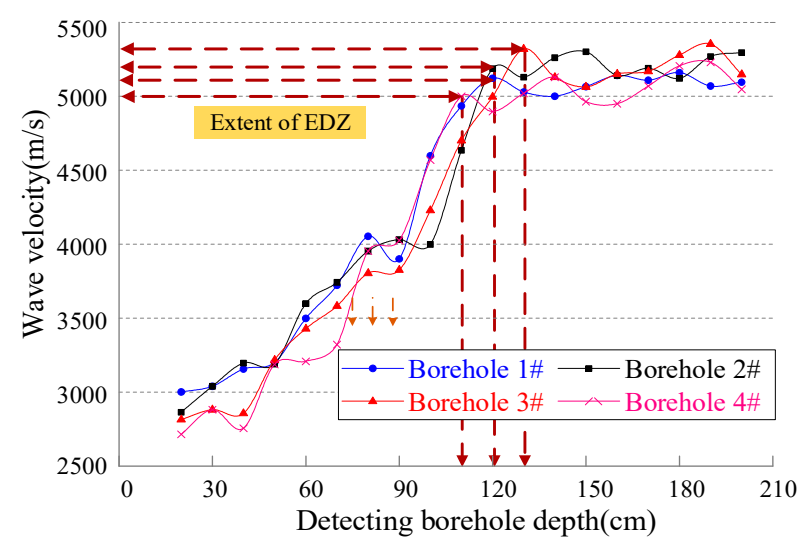

(a)

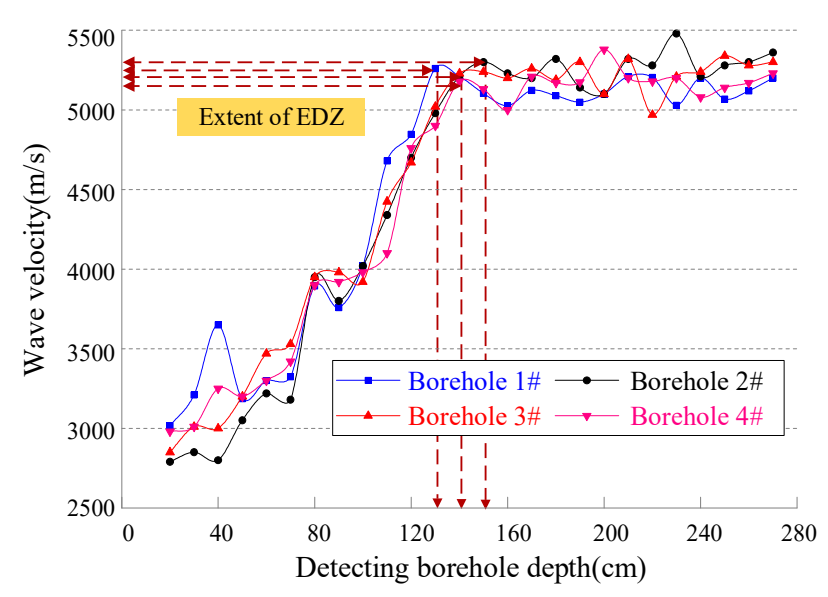

(b)

Figure 4. Cont. 


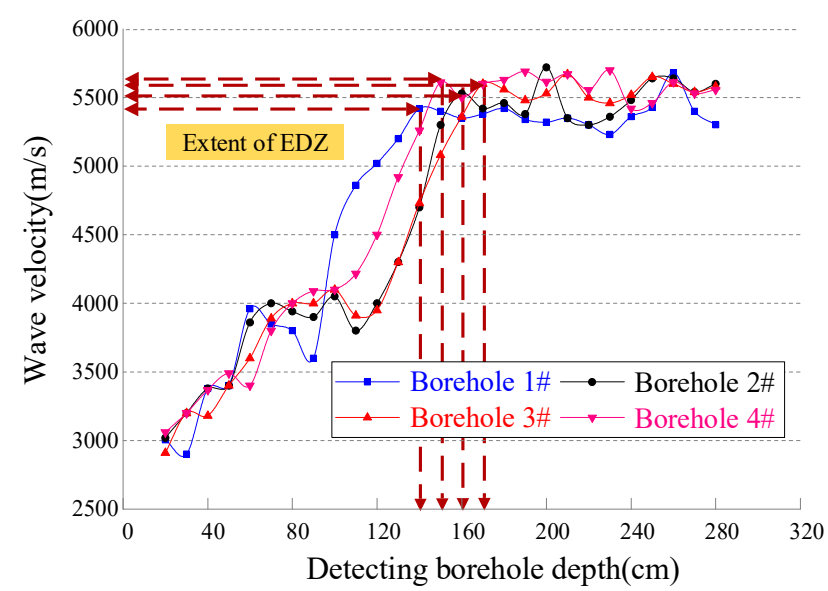

(c)

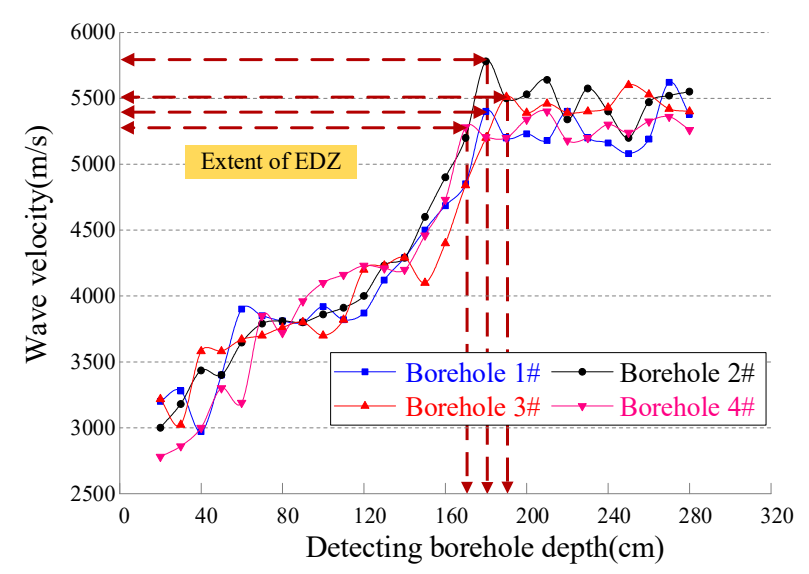

(d)

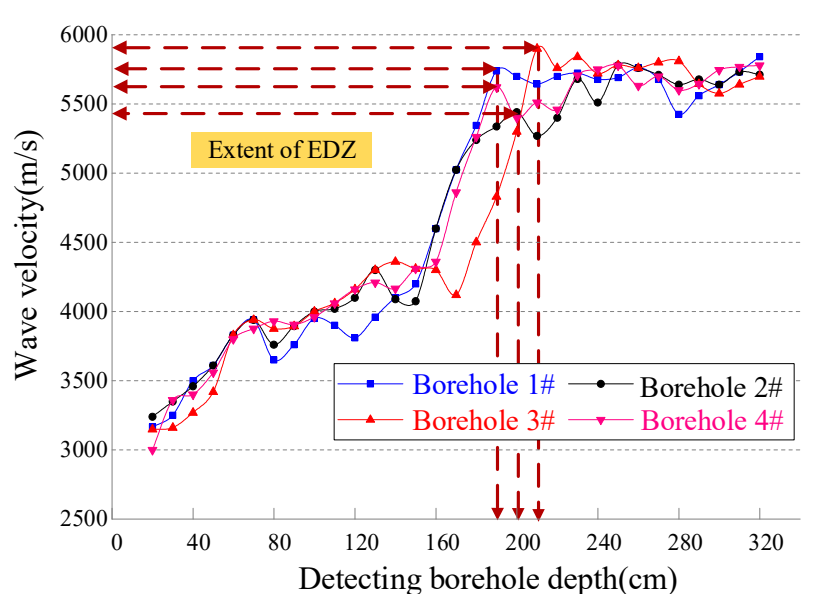

(e)

Figure 4. Field detection results of excavation-damaged zone (EDZ): (a) thickness of EDZ in the roadway I; (b) thickness of EDZ in roadway II; (c) thickness of EDZ in roadway III; (d) thickness of EDZ in roadway IV; (e) thickness of EDZ in roadway V.

As seen in Figure 4, there was an evident low wave velocity region near the roadway surface. Figure $4 \mathrm{a}$ shows that the velocity at depths of 0.2 to $0.8 \mathrm{~m}$ varied in the low range from 2800 to $4000 \mathrm{~m} / \mathrm{s}$ with a relatively slow increase rate, indicating that the rocks were severely damaged, and fractures were well developed in the area. However, there was a slight decline in the acoustic 
velocity, and subsequently, the wave velocity increased sharply within a short period. When the detection devices were set further down the borehole, the velocity slightly fluctuated and stabilized between 5200 and $5400 \mathrm{~m} / \mathrm{s}$. It can be concluded that a damaged zone where the wave velocity had an overall rising stage existed. In addition, a few micro-cracks may have been initiated in rock masses located considerably far from the excavation, but these remained intact. The other variation curves show that changes in the regulations of wave velocity were similar to those shown in Figure 4a. These results indicate that the extent of excavation damage gradually increased as the embedded depth of the roadway increased; that is, the thickness of the EDZ is positively related to the buried depth. On the other hand, it can be shown that the EDZ monitored in boreholes 1\# and 4\# was smaller than that in boreholes $2 \#$ and $3 \#$. The variation of the damage thickness with buried depth was fitted by using the least square method, and the result is shown in Equation (19):

$$
T_{\mathrm{EDZ}}=0.350+0.0023 H
$$

where $T_{\mathrm{EDZ}}$ is the EDZ thickness, and $H$ is the embedded depth of the roadway.

\section{Theoretical Calculations of EDZ Extent in Terms of the Mohr-Coulomb and Hoek-Brown Criteria}

In Section 2, a closed-form solution of EDZ by the Mohr-Coulomb and Hoek-Brown criteria was proposed. Based on the practical conditions of the Fankou lead-zinc mine, the theoretical EDZ thickness was calculated for comparison with field measurement results. The surrounding rock masses were blocky, porphyritic limestone, and dolomitic marl. The parameters of the rock mass and material constants for the Mohr-Coulomb and Hoek-Brown failure criteria, determined by site investigations and laboratory experiments, are listed in Tables 3 and 4, respectively.

Table 3. Rock mass parameters.

\begin{tabular}{cccccc}
\hline Number & $\begin{array}{c}\text { Density } \\
\left(\mathbf{k g} \cdot \mathbf{m}^{-\mathbf{3}} \mathbf{)}\right.\end{array}$ & $\begin{array}{c}\text { Young's Modulus } \\
\mathbf{( G P a )}\end{array}$ & Poisson's Ratio & $\begin{array}{c}\text { Vertical Principal Stress } \\
\mathbf{( M P a )}\end{array}$ & $\begin{array}{c}\text { Lateral Pressure } \\
\text { Coefficient }\end{array}$ \\
\hline I & 2740 & 15.27 & 0.25 & 10.39 & 1.30 \\
II & 2632 & 18.49 & 0.23 & 12.82 & 1.24 \\
III & 2845 & 21.52 & 0.24 & 15.39 & 1.18 \\
IV & 2786 & 17.21 & 0.25 & 19.80 & 1.25 \\
V & 2801 & 19.51 & 0.27 & 22.69 & 1.15 \\
\hline
\end{tabular}

Table 4. Physical and mechanical parameters for Mohr-Coulomb and Hoek-Brown criteria.

\begin{tabular}{ccccccc}
\hline Number & $\begin{array}{c}\text { Cohesion } \\
(\mathbf{M P a})\end{array}$ & $\begin{array}{c}\text { Friction } \\
\text { Angle }\left(^{\circ}\right)\end{array}$ & $\boldsymbol{m}_{\boldsymbol{i}}$ & GSI & $\begin{array}{c}\text { Disturbance Factor } \\
(\mathbf{D})\end{array}$ & $\begin{array}{c}\text { Uniaxial Compressive } \\
\text { Strength (MPa) }\end{array}$ \\
\hline I & 4.8 & 21.35 & 12 & 39 & 0.40 & 145.00 \\
II & 5.0 & 20.00 & 15 & 37 & 0.50 & 130.50 \\
III & 5.3 & 20.36 & 17 & 40 & 0.60 & 141.45 \\
IV & 6.0 & 18.15 & 10 & 40 & 0.40 & 135.27 \\
V & 5.7 & 20.60 & 7 & 42 & 0.25 & 150.66 \\
\hline
\end{tabular}

\subsection{Results Based on the Mohr-Coulomb Failure Criterion}

Based on Equation (6), the EDZ thickness is equal to the deviator radius $\left(R_{p}-R_{0}\right)$. The calculated EDZ ranges in the surrounding rock mass of underground roadways are presented in Figure 5. 


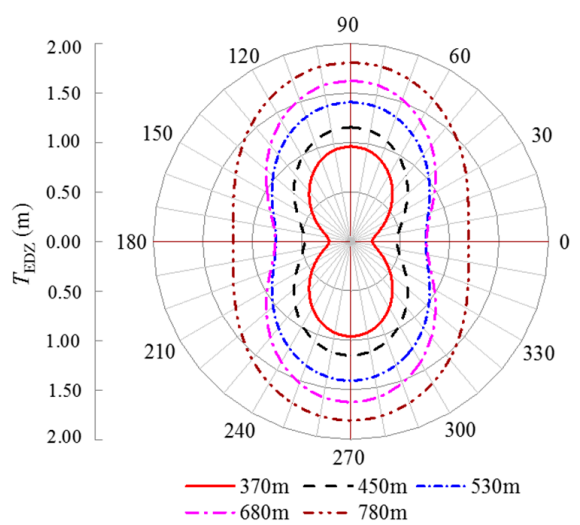

Figure 5. The thickness of EDZs based on the Mohr-Coulomb criterion.

It is shown from Figure 5 that the EDZ size was related to inclination; the EDZ in the vertical direction was always larger than that in the horizontal direction because of the non-hydrostatic stresses field. Corresponding to the field roadways in the Fankou lead-zinc mine, EDZs on the sidewalls are smaller than those on the roof. In addition, the EDZ extent gradually increased as the embedded depth increased. When the depth was $780 \mathrm{~m}$, the extents of damage in the vertical and horizontal directions were 1.79 and $1.19 \mathrm{~m}$, respectively, and their ratio was 1.50 . On the other hand, the thicknesses in the vertical direction were $0.835,0.836,0.886,0.816$, and 0.783 times the average values measured in the field at mining depths of 370, 450, 530, 680, and $780 \mathrm{~m}$, respectively. It was found that the EDZ thicknesses calculated based on the Mohr-Coulomb criterion were smaller than the actual values measured in rock masses under various geological and geometrical conditions. In fact, once a tunnel is excavated in a deep underground mine, a damaged zone will occur in the surrounding rock masses as a result of redistribution of in situ stress and dynamic disturbance caused by excavation unloading. Our results demonstrated that predicting the extent of an EDZ in terms of the Mohr-Coulomb failure criterion has a high reliability.

\subsection{Results Based on the Hoek-Brown Failure Criterion}

By substituting the Hoek-Brown constants and parameters of roadways listed in Tables 3 and 4 into Equation (14), the ranges of EDZs in the surrounding rock mass around underground roadways were obtained, as shown in Figure 6.

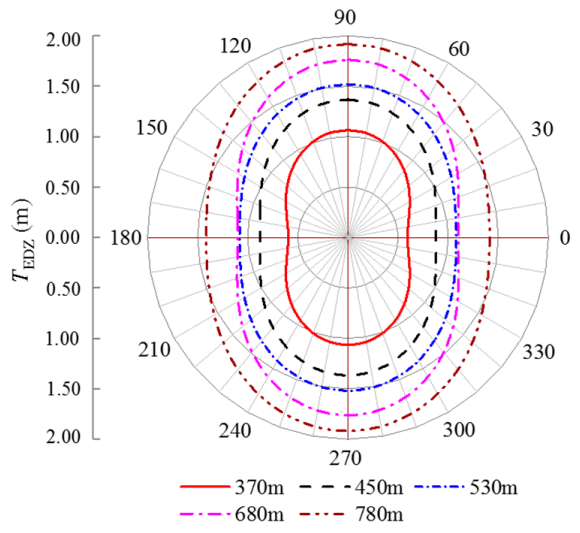

Figure 6. The thickness of EDZs based on the Hoek-Brown criterion.

The results also showed that the EDZ contours obtained in terms of the Hoek-Brown criterion were elliptical. In other words, the EDZ in the vertical direction was always larger than that in the horizontal direction. It was concluded that the maximum calculated EDZ thicknesses were 1.064, 1.367, 1.519, 1.763, and $1.917 \mathrm{~m}$ at each depth, from shallow to deep. On the other hand, the average EDZ thicknesses measured in the field were 1.118, 1.086, 1.033, 1.013, and 1.129 times the average values calculated based on the 
Hoek-Brown criterion in the vertical direction. The deviations between the theoretical calculated EDZ thickness and field measured EDZ thickness did not exceed 12\%. Thus, this failure criterion has high accuracy in predicting EDZ thickness. Because the Hoek-Brown criterion is a semi-empirical strength criterion, the EDZ radius was determined based on rock mass parameters. Consequently, changes in the rock mass parameters were related to significant differences among EDZs.

The calculated thicknesses based on the Hoek-Brown criterion were 6.6 to $11.7 \%$ larger than those calculated based on the Mohr-Coulomb criterion, which demonstrates that the Hoek-Brown criterion achieved better performance than the Mohr-Coulomb criterion in evaluating EDZs surrounding the Fankou lead-zinc mine. In addition, the EDZs assessed with the single-hole acoustic wave monitoring method in the field were larger than those calculated with both the Mohr-Coulomb and Hoek-Brown criteria. These differences may be attributed to the deficient working conditions in the field and the fact that the rock masses in the mining area were not perfectly elastoplastic materials. Additionally, the rock masses were inevitably subjected to dynamic disturbances, such as mechanical drilling, blasting vibration, and stress relief, during excavation. Simultaneously, with the redistribution of in situ stress, the deformations and fractures in the surrounding rock masses continuously deteriorated. Nevertheless, it is important to note that both theoretical solutions in terms of the Hoek-Brown and Mohr-Coulomb failure criteria did not consider the effect of the creep behavior of the rock. Moreover, only a few exact analytical solutions for non-circular tunnel problems have been presented in the literature. Therefore, the difference was inevitable when employing closed-form solutions, derived on the basis of circular openings to evaluate EDZs around these roadways, which have arch and rectangular shapes.

\section{Affecting of EDZ Thickness}

A parametrical study was carried out for the sake of thoroughly investigating the influence of the parameters of Mohr-Coulomb and Hoek-Brown criteria on the stability of excavations in a rock mass with different physical and mechanical properties. Therefore, based on those findings which can provide guidance for practical engineering and provide insight into the characteristics of the rock mass, more rational excavation methods and more stable support systems can be developed. By analyzing Equations (6) and (14), but without considering project conditions, such as $\lambda$ and the tunnel radius, it was found that two key physical coefficients, namely, cohesion and friction angle, affected the calculated EDZ thickness, based on the Mohr-Coulomb criterion. Moreover, four variables, namely, $G S I, m_{i}, D$, and $\sigma_{\mathrm{c}}$ affect the EDZ thickness according to the Hoek-Brown criterion. In the following, the effect of six variables, specifically, $c, \varphi, G S I, m_{i}, D$, and $\sigma_{c}$, on the calculated EDZ thickness are discussed in relation to tunnel construction and support. The other characteristics and stress states of rock masses were assumed to be the same as those of the five roadways in the Fankou lead-zinc mine. Moreover, the following radius of the plastic zone was calculated at $\theta=90^{\circ}$.

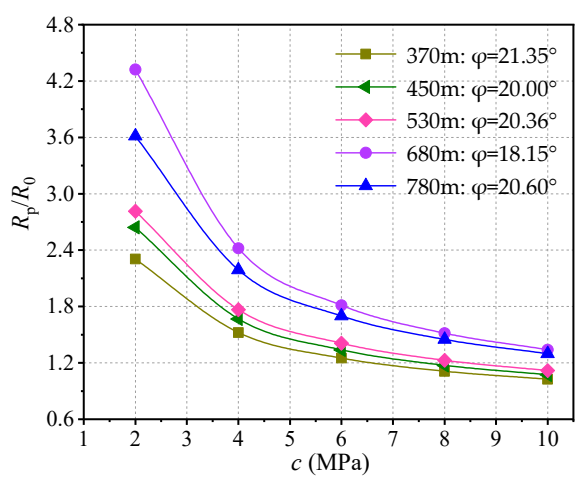

(a)

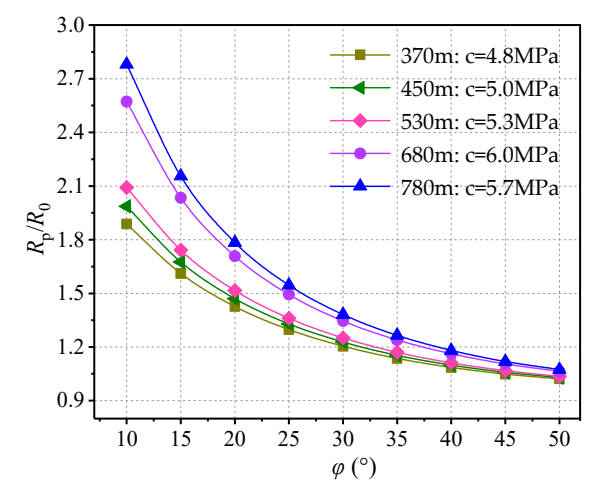

(b)

Figure 7. Cont. 


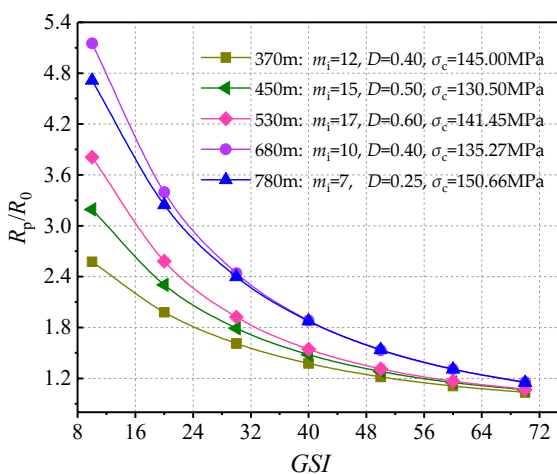

(c)

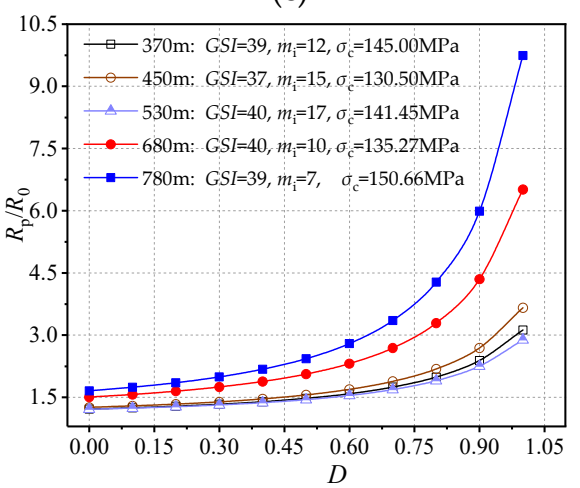

(e)

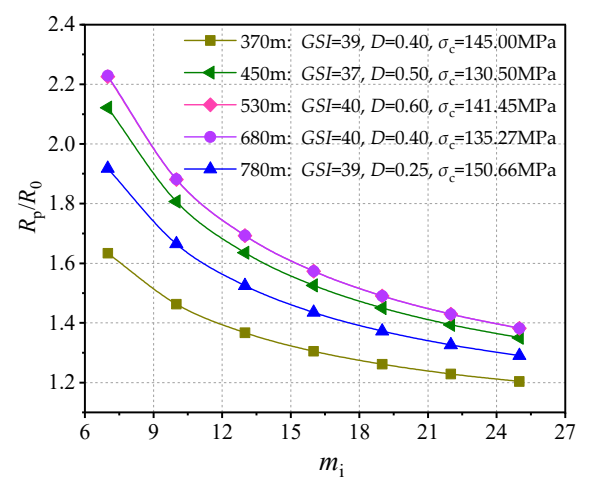

(d)

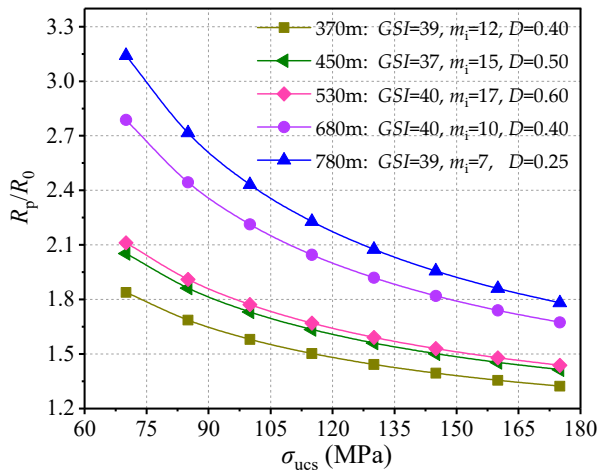

(f)

Figure 7. EDZ thickness variation with different rock mass parameters: (a) effect of $c$ on $R_{0} / R_{\mathrm{p}}$; (b) effect of $\varphi$ on $R_{0} / R_{\mathrm{p}}$; (c) effect of GSI on $R_{0} / R_{\mathrm{p}} ;(\mathbf{d})$ effect of $m_{\mathrm{i}}$ on $R_{0} / R_{\mathrm{p}} ;(\mathbf{e})$ effect of $D$ on $R_{0} / R_{\mathrm{p}} ;(\mathbf{f})$ effect of $\sigma_{\text {ucs }}$ on $R_{0} / R_{\mathrm{p}}$.

As shown in Figure 7a, when the cohesion $c$ is $2 \mathrm{MPa}$, the range of the excavation damage zone is approximately 2.3 to 4.3 times the radius of excavation. In this instance, an increase of $c$ results in a rapid decrease to $R_{p} / R_{0}$. It is indicated that the stability of the roadway can be significantly improved with the increase of cohesion. Nevertheless, once $c$ exceeded $6.0 \mathrm{MPa}$, the increase of $c$ will no longer have an important effect on $R_{p} / R_{0}$. Thus, it is concluded that a minimal damaged zone in surrounding rocks masses with high cohesion $c$ will be induced.

It can be seen in Figure $7 \mathrm{~b}$ that $R_{p} / R_{0}$, which is from 1.9 to 2.78 when the friction angle was $10^{\circ}$, decreases exponentially with the increasing friction angle $\varphi$ of the rocks. Moreover, the extent of EDZ increases with the mining depth. Occasionally, when $\varphi>30^{\circ}$, the effect of the friction angle on $R_{p} / R_{0}$ diminished, although a continuous increase in $\varphi$ further reduced the damaged zone in the surrounding rock. A comparison of the effects of $c$ and $\varphi$ on the integrity of the surrounding rock showed that the effect of $c$ was evidently greater than that of $\varphi$. In underground mining, the instability of rock masses around excavations caused by disturbances of the cohesion and internal friction angle should be minimized.

Figure 7c shows that $R_{p} / R_{0}$ is greatly reduced with an increasing geological strength index GSI value, which is similar to each of the other four field conditions. The ratio of $R_{p}$ to $R_{0}$ approaches 5.15 when $G S I=10$. In this case, an increase in GSI rapidly decreased $R_{\mathrm{p}} / R_{0}$, which means that the stability of the surrounding rocks improved. However, once GSI increases to 40 , the effect on $R_{p} / R_{0}$ was no longer remarkable. Therefore, several techniques, such as deep grouting, spray anchor supporting, and bolt grouting provide remarkable effects on the rock mass integrity and tunnel stability, especially in inadequately jointed rock masses.

The influence of $m_{i}$ on the extent of the damage zone is illustrated in Figure $7 \mathrm{~d}$. Here, there is a negative correlation between the extent of EDZ and $m_{i}$ of the rock mass. The effect of $m_{i}$, which is compared with the influence of GSI on the extent of damage, is quite small. On the other hand, when $m_{i}$ 
increases to 25 , the $R_{p} / R_{0}$ ratios of the five types of cases did not approach 1 , and there is a certain amount of deviation. This result may be attributed to the fact that as the depth of embedment increased, and fractures are inevitably caused in the surrounding rock masses around tunnels under high in situ stress.

The effect of the disturbance factor $D$ on $R_{p} / R_{0}$ is depicted in Figure 7e where a curvilinear trend is seen. The slope increases with the intensity of the dynamic disturbance of rock masses. When $D>0.6$, the influence on the EDZ becomes even more evident, especially for deeply embedded rock masses. These results demonstrate that the dynamic disturbance had an evident weakening effect on the stability and integrity of rock masses under high in situ stress. Hence, for practical mining engineering, the disturbance factor, $D$, should not be larger than 0.6. Otherwise, the thickness of the EDZ will be considerably affected. In the construction of underground projects, it is necessary to include measures to decrease $D$, such as smooth and presplit blasting, decoupled charging, and delayed detonation.

Figure $7 \mathrm{f}$ shows that the range of EDZ increases with the increase of $\sigma_{c}$. When the uniaxial compressive strength of the rock is $70 \mathrm{MPa}$, the ratio of the damaged radius to tunnel radius is approximately 3.14 , and the variation trend of $R_{p} / R_{0}$ at $780 \mathrm{~m}$ is similar to those of the other four types of rock masses. When the uniaxial compressive strength of the rock increase and reaches to $115 \mathrm{MPa}$, the effect of $\sigma_{\mathrm{c}}$ on $R_{p} / R_{0}$ diminishes. Thus, in the construction of openings in rock masses with $\sigma_{\mathcal{c}}$ less than $115 \mathrm{MPa}$, reinforcing supports for the excavation should be considered.

In conclusion, the stability and integrity of a rock mass are positively correlated with $c, \varphi, G S I, m_{i}$, and $\sigma_{c}$. On the contrary, the parameter $D$ varied from 0 to 1 has a weakening effect on the stability of tunnels. In other words, thanks to the action of dynamic disturbance, an extensive EDZ will be induced in rock mass subjected to high in situ stresses. It is noteworthy that $\varphi, G S I$, and $D$ had more significant effects on the extent of EDZ than the other three characteristics. Thus, in tunnel construction, measures to reduce the extent of EDZs in rock masses with varying physical and mechanical characteristics should be carefully considered. In addition, some measures should be adopted to control the expansion of damaged zones, such as pre-grouting, bolt installation coupled with cables, decoupled charging, and so forth.

\section{Conclusions}

During the excavation of underground tunnels in mining, hydropower and radioactive waste disposal operations, an unexpected excavation damaged zone is induced around the tunnels. In this paper, closed-form solutions based on the Mohr-Coulomb and Hoek-Brown failure criteria are derived for predicting the extent of EDZ in the surrounding rock mass around a circular opening subjected to a non-hydrostatic stress field. In addition, the distribution law of in situ stress field in the Fankou lead-zinc mine was analyzed by the overcoring method (stress relief method) accompanying the Swedish high-precision LUT system. The results indicate that $\sigma_{h-\max }, \sigma_{h \text {-min }}$, and $\sigma_{v}$ of the mining area increase approximately linearly with the depth, and the in situ stress field is dominated by maximum horizontal tectonic stress, followed by vertical principal stress. An evaluation of EDZ is carried out by using a SET-PLT-01 nonmetallic ultrasonic detector. It is shown that the thickness of EDZ in the surrounding rock mass shows a linearly increasing trend with depth, and they are greater on the roof-floor region than those on the sidewall. A case study is presented to verify the accuracy of the proposed closed-form solutions in terms of field measurements. The results show that the thicknesses calculated based on Hoek-Brown criterion were 6.6 to $11.7 \%$ larger than those based on the Mohr-Coulomb criterion; thus, it reveals that Hoek-Brown criterion achieved a better performance than the Mohr-Coulomb criterion in EDZ evaluation. The damage thickness assessed with the single-hole acoustic wave monitoring method was approximately 12 to $21 \%$ larger than that calculated under the two derived analytical solutions. The results of the parametric studies illustrate that parameters $c, \varphi, G S I$, and $\sigma_{c}$ have a significant effect on EDZ. Inevitable dynamic disturbance $D$ shows a more critical influence on the stability of underground rock mass. Therefore, the study on evaluating the damage zone around underground openings by theoretical calculation and field 
test methods will be a great help in understanding the evolution law of in situ stresses and EDZ with the depth. The work could also find its application in the field to predict the extent of the excavation-damaged zone under the premise that the physical and mechanical properties of rock mass have been obtained.

Author Contributions: This paper is a result of the collaboration of all co-authors. M.T. conceived and designed the study; Z.H. derived two closed-form solutions, sorted out the experimental data, and drafted the manuscript; P.S. and M.C. provided on-site testing guidance of in situ stresses and excavation damaged zone; K.D. provided the experimental platform and guidance. In addition, M.T., K.P., and K.D. revised the paper. All authors have read and approved the final manuscript.

Funding: The research presented in this paper is supported by the National Natural Science Foundation of China (Grant No. 11772357, 41630642).

Conflicts of Interest: The authors declare no conflicts of interest.

\section{References}

1. Cho, W.J.; Kim, J.S.; Lee, C.I.; Choi, H.J. Gas permeability in the excavation damaged zone at KURT. Eng. Geol. 2013, 164, 222-229. [CrossRef]

2. Kwon, S.; Cho, W.J. The influence of an excavation damaged zone on the thermal-mechanical and hydro-mechanical behaviors of an underground excavation. Eng. Geol. 2008, 101, 110-123. [CrossRef]

3. Kim, H.M.; Rutqvist, J.; Jeong, J.H.; Choi, B.H.; Ryu, D.W.; Song, W.K. Characterizing excavation damaged zone and stability of pressurized lined rock caverns for underground compressed air energy storage. Rock Mech. Rock Eng. 2013, 46, 1113-1124. [CrossRef]

4. Ma, D.; Rezania, M.; Yu, H.S.; Bai, H.B. Variations of hydraulic properties of granular sandstones during water inrush: Effect of small particle migration. Eng. Geol. 2017, 217, 61-70. [CrossRef]

5. Suchowerska, A.M.; Merifield, R.S.; Carter, J.P.; Clausen, J. Prediction of underground cavity roof collapse using the Hoek-Brown failure criterion. Comput. Geotech. 2012, 44, 93-103. [CrossRef]

6. Yang, J.P.; Chen, W.Z.; Zhao, W.S.; Tan, X.J.; Tian, H.M.; Yang, D.S.; Ma, C.S. Geohazards of tunnel excavation in interbedded layers under high in situ stress. Eng. Geol. 2017, 230, 11-22. [CrossRef]

7. Feng, X.W.; Nong, Z.; Gong, L.Y.; Fei, X.; Zheng, X.G. Application of a Backfilling Method in Coal Mining to Realise an Ecologically Sensitive “Black Gold" Industry. Energies 2015, 8, 3628-3639. [CrossRef]

8. Zhou, Z.L.; Cheng, R.S.; Cai, X.; Ma, D.; Jiang, C. Discrimination of Rock Fracture and Blast Events Based on Signal Complexity and Machine Learning. Shock Vib. 2018. [CrossRef]

9. Zhang, Q.; Jiang, B.S.; Wang, S.L.; Ge, X.R.; Zhang, H.Q. Elasto-plastic analysis of a circular opening in strain-softening rock mass. Int. J. Rock Mech. Min. Sci. 2012, 50, 38-46. [CrossRef]

10. Kwon, S.; Lee, C.S.; Cho, S.J.; Jeon, S.W.; Cho, W.J. An investigation of the excavation damaged zone at the KAERI underground research tunnel. Tunn. Undergr. Space Technol. 2009, 24, 1-13. [CrossRef]

11. Tang, S.B.; Yu, C.Y.; Tang, C.A. Numerical modeling of the time-dependent development of the damage zone around a tunnel under high humidity conditions. Tunn. Undergr. Space Technol. 2018, 76, 48-63. [CrossRef]

12. Souley, M.; Renaud, V.; Al Heib, M.; Bouffier, C.; Lahaie, F.; Nyström, A. Numerical investigation of the development of the excavation damaged zone around a deep polymetallic ore mine. Int. J. Rock Mech. Min. Sci. 2018, 106, 165-175. [CrossRef]

13. Wu, F.Q.; Liu, J.Y.; Liu, T.; Zhuang, H.Z.; Yan, C.G. A method for assessment of excavation damaged zone (EDZ) of a rock mass and its application to a dam foundation case. Eng. Geol. 2009, 104, 254-262. [CrossRef]

14. Sharan, S.K. Elastic-brittle-plastic analysis of circular openings in Hoek-Brown media. Int. J. Rock Mech. Min. Sci. 2003, 40, 817-824. [CrossRef]

15. Zareifard, M.R.; Fahimifar, A. Analytical solutions for the stresses and deformations of deep tunnels in an elastic-brittle-plastic rock mass considering the damaged zone. Tunn. Undergr. Space Technol. 2016, 58, 186-196. [CrossRef]

16. Carranza-Torres, C. Elasto-plastic solution of tunnel problems using the generalized form of the hoek-brown failure criterion. Int. J. Rock Mech. Min. Sci. 2004, 41, 629-639. [CrossRef]

17. Park, K.H.; Kim, Y.J. Analytical solution for a circular opening in an elastic-brittle-plastic rock. Int. J. Rock Mech. Min. Sci. 2006, 43, 616-622. [CrossRef] 
18. Roateşi, S. Analytical and numerical approach for tunnel face advance in a viscoplastic rock mass. Int. J. Rock Mech. Min. Sci. 2014, 70, 123-132. [CrossRef]

19. Singh, A.; Rao, K.S.; Ayothiraman, R. Effect of intermediate principal stress on cylindrical tunnel in an elasto-plastic rock mass. Proc. Eng. 2017, 173, 1056-1063. [CrossRef]

20. Huang, H.X.; Li, J.; Rong, X.L.; Hao, Y.Q.; Dong, X. A displacement solution for circular openings in an elastic-brittle-plastic rock. Geomech. Eng. 2017, 13, 489-504. [CrossRef]

21. Vrakas, A.; Anagnostou, G. A finite strain closed-form solution for the elastoplastic ground response curve in tunnelling. Int. J. Numer. Anal, Method. Geomech. 2014, 38, 1131-1148. [CrossRef]

22. Zhou, X.P.; Li, J.L. Hoek-Brown criterion applied to circular tunnel using elastoplasticity and in situ axial stress. Theor. Appl. Fract. Mec. 2011, 56, 95-103. [CrossRef]

23. Liang, Z.Z.; Gong, B.; Li, W.R. Instability analysis of a deep tunnel under triaxial loads using a three-dimensional numerical method with strength reduction method. Tunn. Undergr. Space Technol. 2019, 86, 51-62. [CrossRef]

24. Lu, A.Z.; Xu, G.S.; Sun, F.; Sun, W.Q. Elasto-plastic analysis of a circular tunnel including the effect of the axial in situ stress. Int. J. Rock Mech. Min. Sci. 2010, 47, 50-59. [CrossRef]

25. Liu, K.W.; Li, X.D.; Hao, H.; Li, X.B.; Sha, Y.Y.; Wang, W.H.; Liu, X.L. Study on the raising technique using one blast based on the combination of long-hole presplitting and vertical crater retreat multiple-deck shots. Int. J. Rock Mech. Min. Sci. 2019, 113, 41-58. [CrossRef]

26. Yang, J.H.; Jiang, Q.H.; Zhang, Q.B.; Zhao, J. Dynamic stress adjustment and rock damage during blasting excavation in a deep-buried circular tunnel. Tunn. Undergr. Space Technol. 2018, 71, 591-604. [CrossRef]

27. Wang, S.H.; Lee, C.I.; Ranjith, P.G.; Tang, C.A. Modeling the Effects of Heterogeneity and Anisotropy on the Excavation Damaged/Disturbed Zone (EDZ). Rock Mech. Rock Eng. 2009, 42, 229-258. [CrossRef]

28. Kim, J.T.; Hong, K.B.; Ryou, H.S. Numerical Analysis on the Effect of the Tunnel Slope on the Plug-Holing Phenomena. Energies 2018, 12, 59. [CrossRef]

29. Golshani, A.; Oda, M.; Okui, Y.; Takemura, T.; Munkhtogoo, E. Numerical simulation of the excavation damaged zone around an opening in brittle rock. Int. J. Rock Mech. Min. Sci. 2007, 44, 835-845. [CrossRef]

30. Yang, H.Q.; Zeng, Y.Y.; Lan, Y.F.; Zhou, X.P. Analysis of the excavation damaged zone around a tunnel accounting for geostress and unloading. Int. J. Rock Mech. Min. Sci. 2014, 69, 59-66. [CrossRef]

31. Perras, M.A.; Diederichs, M.S. Predicting excavation damage zone depths in brittle rocks. J. Rock Mech. Geotech. Eng. 2016, 8, 60-74. [CrossRef]

32. Ren, M.; Zhang, Q.; Liu, C.; Wu, D.; Ding, Y. The Elastic-Plastic Damage Analysis of Underground Research Laboratory Excavation for Disposal of High Level Radioactive Waste. Geotechnical and Geological Engineering. 2018. [CrossRef]

33. Wu, Z.; Jiang, Y.; Liu, Q.; Ma, H. Investigation of the excavation damaged zone around deep TBM tunnel using a Voronoi-element based explicit numerical manifold method. Int. J. Rock Mech. Min. Sci. 2018, 112, 158-170. [CrossRef]

34. Zhu, W.C.; Bruhns, O.T. Simulating excavation damaged zone around a circular opening under hydromechanical conditions. Int. J. Rock Mech. Min. Sci. 2008, 45, 815-830. [CrossRef]

35. Sofianos, A.I.; Halakatevakis, N. Equivalent tunnelling Mohr-Coulomb strength parameters for given Hoek-Brown ones. Int. J. Rock Mech. Min. Sci. 2002, 39, 131-137. [CrossRef]

36. Hoek, E.; Brown, E.T. The Hoek-Brown failure criterion and GSI-2018 edition. J. Rock Mech. Geotech. Eng. 2018. [CrossRef]

37. Jimenez, R.; Serrano, A.; Olalla, C. Linearization of the Hoek and Brown rock failure criterion for tunnelling in elasto-plastic rock masses. Int. J. Rock Mech. Min. Sci. 2008, 45, 1153-1163. [CrossRef]

38. Wu, S.C.; Zhang, S.H.; Zhang, G. Three-dimensional strength estimation of intact rocks using a modified Hoek-Brown criterion based on a new deviatoric function. Int. J. Rock Mech. Min. Sci. 2018, 107, 181-190. [CrossRef]

39. Cai, M.; Kaiser, P.K.; Tasaka, Y.; Maejima, T.; Morioka, H.; Minami, M. Generalized crack initiation and crack damage stress thresholds of brittle rock masses near underground excavations. Int. J. Rock Mech. Min. Sci. 2004, 41, 833-847. [CrossRef]

40. Wang, H.W.; Jiang, Y.D.; Xue, S.; Shen, B.T.; Wang, C.; Lv, J.G.; Yang, T. Assessment of excavation damaged zone around roadways under dynamic pressure induced by an active mining process. Int. J. Rock Mech. Min. Sci. 2015, 77, 265-277. [CrossRef] 
41. Li, H.; Liu, M.; Xing, W.; Shao, S.; Zhou, J. Failure Mechanisms and Evolution Assessment of the Excavation Damaged Zones in a Large-Scale and Deeply Buried Underground Powerhouse. Rock Mech. Rock Eng. 2017, 50, 1883-1900. [CrossRef]

42. Yong, S.; Loew, S.; Schuster, K.; Nussbaum, C.; Fidelibus, C. Characterisation of Excavation-Induced Damage Around a Short Test Tunnel in the Opalinus Clay. Rock Mech. Rock Eng. 2017, 50, 1959-1985. [CrossRef]

(c)

(C) 2019 by the authors. Licensee MDPI, Basel, Switzerland. This article is an open access article distributed under the terms and conditions of the Creative Commons Attribution (CC BY) license (http://creativecommons.org/licenses/by/4.0/). 